\title{
In vitro assessment of time-dependent changes in red cell cytoplasmic antioxidants of donkey blood preserved in citrate phosphate dextrose adenine 1 anticoagulant
}

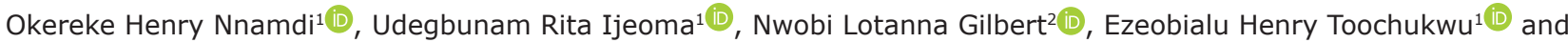 \\ Udegbunam Sunday Ositadinma ${ }^{1,3}$
}

1. Department of Veterinary Surgery, Faculty of Veterinary Medicine, University of Nigeria, Enugu State, Nigeria; 2. Department of Veterinary Physiology and Pharmacology, Faculty of Veterinary Medicine, University of Nigeria, Enugu State, Nigeria; 3. Veterinary Teaching Hospital, Faculty of Veterinary Medicine, University of Nigeria, Enugu State, Nigeria. Corresponding author: Okereke Henry Nnamdi, e-mail: nnamdi.okereke@unn.edu.ng

Co-authors: URI: rita.udegbunam@unn.edu.ng, NLG: lotanna.nwobi@unn.edu.ng, EHT: ezeobialuhenry@gmail.com, USO: sunday.udegbunam@unn.edu.ng

Received: 20-12-2019, Accepted: 09-03-2020, Published online: 19-04-2020

doi: www.doi.org/10.14202/vetworld.2020.726-730 How to cite this article: Nnamdi OH, Ijeoma UR, Gilbert NL, Toochukwu EH, Ositadinma US (2020) In vitro assessment of time-dependent changes in red cell cytoplasmic antioxidants of donkey blood preserved in citrate phosphate dextrose adenine 1 anticoagulant, Veterinary World, 13(4): 726-730.

\begin{abstract}
Background and Aim: Stored blood is continuously exposed to oxidative stress, which affects its antioxidant protective system. Erythrocytes are naturally armed with antioxidant protective capacity. Blood antioxidant system functions to protect the blood cells against oxidative damage by free radicals. However, during storage, blood is continuously exposed to oxidative stress, which affects its antioxidant system. The aim of this work was to investigate alteration in malondialdehyde (MDA) levels, reduced glutathione (glutathione reductase [GSH-Rd]), catalase (CAT), and superoxide dismutase (SOD) activities in stored donkey blood.
\end{abstract}

Materials and Methods: Blood $(250 \mathrm{ml})$ was drawn from four clinically healthy donkeys into citrate phosphate dextrose adenine 1 blood bags and preserved at $4^{\circ} \mathrm{C}$. MDA, GSH-Rd, CAT, and SOD activities were assayed by colorimetric methods, over a period of 42 days.

Results: The result showed that SOD enzyme activities significantly $(\mathrm{p}<0.05)$ increased by day 7 post-storage (PS) while MDA levels significantly $(\mathrm{p}<0.05)$ increased by day 21 PS. However, activities of GSH-Rd and CAT enzymes decreased $(\mathrm{p}<0.05)$ by day 21 PS. Pearson's product-moment correlation showed a negative correlation between the levels of MDA and enzymatic antioxidant markers (CAT and GSH-Rd).

Conclusion: The findings revealed that GSH-Rd and CAT are the primary antioxidant defense markers in donkey red blood cells. The observed alterations in these principal antioxidants suggest a 14 days optimum keeping time of donkey blood for blood banking purposes.

Keywords: blood, citrate phosphate dextrose adenine 1, donkey, malondialdehyde, superoxide dismutase.

\section{Introduction}

Storage media available for the preservation of blood meant for transfusion purposes maintain the viability and oxygen-carrying capacity of the collected blood [1-4]. At present, anticoagulants recommended for use include citrate phosphate dextrose (CPD), CPD adenine (CPDA-1), acid citrate dextrose, storage media for blood, heparin, and a whole lot of others [1,5]. The Food and Drug Administration permits blood to be stored up to 42 days before transfusion with the use of CPDA-1 anticoagulant. Citrate in the media functions to bind the ionized calcium present in whole blood and thus inhibits several steps in the coagulation cascade while dextrose allows

Copyright: Nnamdi, et al. Open Access. This article is distributed under the terms of the Creative Commons Attribution 4.0 International License (http://creativecommons.org/licenses/ by/4.0/), which permits unrestricted use, distribution, and reproduction in any medium, provided you give appropriate credit to the original author(s) and the source, provide a link to the Creative Commons license, and indicate if changes were made. The Creative Commons Public Domain Dedication waiver (http:// creativecommons.org/publicdomain/zero/1.0/) applies to the data made available in this article, unless otherwise stated. generation of adenosine triphosphate (ATP) through glycolytic activity. Orlov and Kakouti [2] posited that the maintenance of ATP levels correlates with red cell viability. The addition of adenine to the preservative CPDA-1 promotes red cell ATP production, which, in turn, lengthens the shelf-life of stored blood. More so, the presence of phosphorus in the preservative enables the blood to maintain a normal oxygen dissociation curve $[1,6]$.

Blood recipients usually have the need to increase their oxygen-carrying capacity, and in such conditions, blood collected in blood bags are either transfused immediately (fresh blood) or preserved over a period of time (stored blood) $[4,6]$. Stored blood cells undergo biochemical, molecular, metabolic, and biomechanical alterations which occur within the erythrocytes, leading to energetic compromise, which is characterized by ATP and 2,3-diphosphoglycerate (2,3-DPG) depletion as well as loss of red cell membrane integrity [7]. The red blood cell (RBC) membrane damage is caused by the free radicals mediated by lipid and protein oxidation $[2,8]$. 
The defense mechanism of blood cells against oxidative damage is their cell membrane antioxidant system consisting of superoxide dismutase (SOD), reduced glutathione (glutathione reductase [GSH-Rd]), and catalase (CAT). Under normal physiological conditions, there is a balance between $\mathrm{RBC}$ antioxidant system and free radicals [2,8-10]. Blood storage lesion occurs in conditions when the blood has been in the storage medium for a long time. In such conditions, blood antioxidant system may not be able to protect the blood cells against oxidative damage by free radicals and this has a negative effect on blood quality during storage [11]. In our locality, due to the increasing need for transfusion therapy in animals, including donkeys and the unavailability of specially designed blood bags for these breed of animals, the common practice is to make use of commercially available human blood bag with CPDA-1 preservatives. However, to date, no empirical study has evaluated the changes in the principal cellular RBC membrane antioxidants of donkey blood preserved with commercially available blood bags meant for humans.

\section{Materials and Methods}

\section{Ethical approval}

The experimental protocols used in this study were approved by the Ethics Committee of the University of Nigeria, Nsukka, and conform with the Guide for the Care and Use of Agricultural Animals in Research and Teaching of University of Nigeria, Nsukka, Enugu State, Nigeria.

\section{Study period and Animals}

The duration of this study was from May to July 2019. Four adult male donkeys used for this study were judged to be healthy on the basis of clinical and hematological examinations. They were managed semi-intensively at the Veterinary farm of the Faculty of Veterinary Medicine, University of Nigeria, Nsukka, Enugu State, Nigeria.

\section{Methodology}

Two hundred and fifty milliliters of blood each were drawn from four clinically healthy donkeys into humans (infant) CPDA-1 blood bags (Richter ${ }^{\circledR}$, China). The samples were aseptically collected within $20 \mathrm{~min}$, thoroughly but gently mixed with the anticoagulant; immediately, the blood was drawn from the jugular vein of the donkeys and also after filling the bags. Blood was preserved at $4{ }^{\circ} \mathrm{C}$ and parameters assayed on days $0,7,14,21,28,35$, and 42 , and levels of MDA and activities of GSH-Rd, CAT, and SOD were measured by spectrophotometry.

\section{Preparation of hemolysate}

A volume of $1 \mathrm{ml}$ of the blood sample was centrifuged at $2000 \times \mathrm{g}$ for $20 \mathrm{~min}$ and the plasma and buffy coat discarded. The RBC was washed 3 times in cold phosphate-buffered saline ( $\mathrm{pH}$ 7.45). A 1:10 hemolysate dilution in ice-cold distilled water was used for the determination of CAT activity. A 1:20 hemolysate in ice-cold distilled water was used for MDA (thiobarbituric acid reactive substance [TBARS]) and SOD measurement. A 1:20 hemolysate in $2.7 \mathrm{mM}$ EDTA and 0.7 $\mathrm{mM}$ 2-mercaptoethanol was used for the determination of GSH-Rd levels. The hemoglobin $(\mathrm{Hb})$ concentrations of the blood and hemolysate were determined based on the cyanmethemoglobin method using a spectrophotometer (CHEM-5V3; Erba, Mannheim, Germany). The concentration of $\mathrm{Hb}(\mathrm{g} / \mathrm{dl})$ was determined by comparing against standard solution of cyanmethemoglobin.

\section{Erythrocyte CAT test}

Erythrocyte CAT activity was determined according to the method described previously by Sinha [12]. In this method, dichromate in acetic acid is reduced to chromic acetate when heated in the presence of hydrogen peroxide $\left(\mathrm{H}_{2} \mathrm{O}_{2}\right)$, with the formation of perchromic acid as an unstable intermediate. Hydrogen peroxide concentration is directly proportional to the concentration of chromic acetate that is produced from the reaction. The chromic acetate produced is measured spectrophotometrically at $570 \mathrm{~nm}$. Briefly, $0.04 \mathrm{ml}$ of the hemolysate was added to $2.96 \mathrm{ml}$ of $\mathrm{H}_{2} \mathrm{O}_{2}(0.2 \mathrm{M})$-phosphate buffer (0.01 M, pH 7). From this mixture, $2 \mathrm{ml}$ of dichromate/acetic acid reagent was used to stop the reaction with an interval of $1 \mathrm{~min}$. The tubes were heated at $100^{\circ} \mathrm{C}$ for $10 \mathrm{~min}$, cooled, and then centrifuged at $2500 \times \mathrm{g}$ for $5 \mathrm{~min}$ to remove precipitated proteins, and the changes in absorbance were recorded at $570 \mathrm{~nm}$ against the reagent blank using a spectrophotometer (Jenway 6305; Jenway, Essex, UK). A standard curve was prepared with 0-200 mMol $\mathrm{H}_{2} \mathrm{O}_{2}$. Erythrocyte CAT activity was expressed in $\mathrm{mMol} \mathrm{H}_{2} \mathrm{O}_{2}$ decomposed $/ \mathrm{min} / \mathrm{g} \mathrm{Hb}$.

\section{Erythrocyte reduced glutathione (GSH-Rd) test}

Reduced glutathione in the erythrocytes was determined according to the method described previously [13]. The principle is based on the formation of a yellow-colored complex when dithionitrobenzene (DTNB) reacts with the acid-soluble sulfhydryl groups (non-protein thiols) of which more than 93\% is reduced glutathione. The absorbance of the colored complex was measured at $412 \mathrm{~nm}$. A volume of $0.5 \mathrm{ml}$ of the hemolysate was mixed with $0.1 \mathrm{ml}$ of $25 \%$ TCA and kept on ice for a few minutes. This was then centrifuged at $3000 \mathrm{~g}$ for $10 \mathrm{~min}$ and $0.3 \mathrm{ml}$ of the supernatant was mixed with $0.7 \mathrm{ml}$ of $0.2 \mathrm{M}$ sodium phosphate buffer ( $\mathrm{pH} 8$ ) and $2 \mathrm{ml}$ of $0.6 \mathrm{mM}$ DTNB (Sigma, St. Louis, MO, USA). After $10 \mathrm{~min}$, the yellow color obtained was measured at $412 \mathrm{~nm}$ using a spectrophotometer (Jenway 6305; Jenway, Essex, UK) against a reagent blank. A standard graph was prepared using different concentrations $(0-100 \mu \mathrm{Mol})$ of GSH (Sigma, St. Louis, MO, USA). The GSH content was calculated with the help of this standard graph and expressed as $\mu \mathrm{Mol} / \mathrm{g} \mathrm{Hb}$.

\section{Erythrocyte malondialdehyde (MDA) test}

Erythrocyte MDA level, an end product of lipid peroxidation, was measured based on the method of 
Stocks and Dormandy [14]. Thiobarbituric acid reacts with MDA to produce a stable chromogen that is quantified by spectrophotometry. The color intensity of the chromogen is measured at $532 \mathrm{~nm}$, which is directly proportional to MDA content. Lipid peroxidation in erythrocytes was quantified by measuring the formation of TBARS based on the method of Stocks and Dormandy (1971). Equal volume of hemolysate $(0.5 \mathrm{ml})$ was mixed with $20 \%$ trichloroacetic acid $(1: 1)$ and incubated at room temperature. Samples were centrifuged at $2500 \times \mathrm{g}$ for $10 \mathrm{~min}$. Then, $1.0 \mathrm{ml}$ of $1 \%$ thiobarbituric acid was added to the supernatant and samples were placed in a boiling water bath $\left(100^{\circ} \mathrm{C}\right)$ for $15 \mathrm{~min}$. The contents were cooled on ice and centrifuged for $15 \mathrm{~min}$ at $2500 \times \mathrm{g}$. The absorbance (A) of the supernatant was read at $532 \mathrm{~nm}$ against a reagent blank using a spectrophotometer (Jenway 6305; Jenway, Essex, UK). A standard graph was prepared using different concentrations (0-20 nMoles) of MDA (Sigma, St. Louis, MO, USA). Lipid peroxidation (TBARS) level in the erythrocytes was expressed in $\mathrm{nMol} / \mathrm{g} \mathrm{Hb}$.

\section{Erythrocyte SOD test}

SOD activity in the erythrocytes was determined according to the method developed by Misra and Fridovich [15]. The test is based on the ability of SOD to inhibit the autoxidation of epinephrine to adrenochrome at $\mathrm{pH}$ 10.2. A volume of $0.5 \mathrm{ml}$ of hemolysate was diluted with an equal volume of distilled water, followed by the addition of $0.25 \mathrm{ml}$ of ice-cold ethanol and $0.15 \mathrm{ml}$ of ice-cold chloroform. This was thoroughly mixed using a cyclomixer and then centrifuged at $2500 \times \mathrm{g}$ for $10 \mathrm{~min}$. The supernatant was mixed with $1.5 \mathrm{ml}$ of carbonate buffer $(0.05 \mathrm{M}, \mathrm{pH} 10.2)$ and $0.5 \mathrm{ml}$ of $0.5 \mathrm{mM}$ EDTA solution. The reaction was initiated by the addition of $0.4 \mathrm{ml}$ of $3 \mathrm{mM}$ epinephrine (Sigma, St. Louis, MO, USA) and the change in absorbance per minute was measured at $480 \mathrm{~nm}$ against a reagent blank. The enzyme unit was defined as the change in absorbance per minute at 50\% inhibition of epinephrine to adrenochrome by SOD. An enzyme calibration curve was prepared using 0-195 units of SOD (Sigma, St. Louis, MO, USA). SOD activity was expressed in $\mathrm{U} / \mathrm{g} \mathrm{Hb}$.

\section{Statistical analysis}

The calculated values were entered into Microsoft Excel sheet for documentation and analysis. SPSS version 21 (IBM Corp., NY, USA) was used for statistical analysis. Mean, standard error of mean, and confidence intervals were determined for each analyzed variable. Data collected were statistically compared within group using one-way analysis of variance. The least significant difference post hoc test was used to separate the variant means at $p<0.05$ as statistically significant. Pearson's product-moment correlation was run to determine the magnitude and direction between the oxidative and antioxidative enzymes changes that occurred during storage. Correlation of variant means at $\mathrm{p}<0.01$ and $\mathrm{p}<0.05$ was used as statistically significant.

\section{Results}

This study showed that there was a progressive significant $(p<0.05)$ decrease from the baseline in GSH-Rd and CAT enzyme activity from day 21 to day 42 of blood storage. Furthermore, SOD enzyme activity significantly $(\mathrm{p}<0.05)$ decreased by day 7 blood storage (Table-1), but no significant $(\mathrm{p}>0.05)$ variation was observed from SOD results between days 7 and 28 of blood storage. The findings of MDA levels revealed a progressive significant $(\mathrm{p}<0.05)$ increase throughout the blood storage duration (Table-1).

Pearson's product-moment correlation coefficient was used to determine the magnitude and direction of association between the oxidative marker (levels of MDA) and the antioxidant enzymes (SOD, CAT, and GSH-Rd). The result of the test showed a negative correlation between the MDA levels and activities of CAT $(\mathrm{r}=-0.717, \mathrm{n}=28, \mathrm{p}<0.000)$ and GSH-Rd $(\mathrm{r}=-0.608$, $\mathrm{n}=28, \mathrm{p}<0.001)$. However, no significant variation was recorded between the levels of MDA and activities of SOD $(r=-0.363, n=28, p<0.06)$.

\section{Discussion}

Blood stored in standard blood banking conditions for transfusion or experimental purposes undergo time-dependent changes [3]. These changes include loss of membrane and cytosolic antioxidant enzymes, alterations in lipids and structural membrane proteins, loss of 2,3-DPG, and ATP [2]. These changes possibly lead to unsatisfactory post-transfusion reactions in the patient [4].

In this study, levels of MDA, as well as activities of CAT, GSH-Rd, and SOD, were assayed on

Table-1: Changes in the mean oxidative and antioxidative parameters of CPDA-1 stored canine blood (Mean \pm SE).

\begin{tabular}{|c|c|c|c|c|}
\hline Days & MDA (nMol/gHb) & SOD (U/gHb) & GSH-Rd ( $\mu \mathrm{Mol} / \mathrm{gHb})$ & CAT ( $\mu \mathrm{Mol} / \mathrm{min} / \mathrm{gHb})$ \\
\hline 0 & $20.9 \pm 0.7^{a}$ & $970.3 \pm 61.9^{a}$ & $6.21 \pm 0.2^{\mathrm{a}}$ & $5.9 \pm 1.0^{a}$ \\
\hline 7 & $31.7 \pm 4.3^{b}$ & $1093.2 \pm 56.3^{b}$ & $6.32 \pm 0.3^{a}$ & $6.0 \pm 0.1^{a}$ \\
\hline 14 & $45.3 \pm 1.9^{c}$ & $992.0 \pm 123.1^{b}$ & $6.66 \pm 0.3^{a}$ & $6.0 \pm 0.0^{a}$ \\
\hline 21 & $72.1 \pm 3.6^{d}$ & $1059.8 \pm 123.8^{b}$ & $2.30 \pm 0.1^{\mathrm{b}}$ & $3.1 \pm 0.1^{\mathrm{b}}$ \\
\hline 28 & $73.1 \pm 1.1^{\mathrm{e}}$ & $1020.3 \pm 39.6^{b}$ & $4.95 \pm 0.1^{b}$ & $3.2 \pm 0.9^{b}$ \\
\hline 35 & $71.9 \pm 1.1^{\mathrm{e}}$ & $746.0 \pm 49.8^{c}$ & $3.85 \pm 0.0^{c}$ & $3.1 \pm 0.1^{\mathrm{b}}$ \\
\hline 42 & $72.0 \pm 3.6^{\mathrm{e}}$ & $611.1 \pm 49.4^{c}$ & $4.08 \pm 0.1^{c}$ & $3.1 \pm 0.4^{b}$ \\
\hline
\end{tabular}

Different superscripts ${ }^{a, b, c, d}$ in a column indicate significant difference between the mean at the level of probability: $(p<0.05) . M D A=$ Malondialdehyde, GSH-Rd=Glutathione reductase, $C T=$ Catalase, SOD=Superoxide dismutase, $\mathrm{SE}=$ Standard error 
days $0,7,14,21,28,35$, and 42 . The major enzymatic systems against free radicals and peroxides include activities of SOD, CAT, and GSH-Rd [16,17]. Blood antioxidant defense mechanisms maintain the free radical levels at physiological limits by acting as oxidation inhibitors. However, during blood storage, oxidative changes remain one of the important findings. Studies in dog and human blood preserved in standard blood banking conditions revealed time-dependent changes vis-a-vis loss of GSH, CAT, and SOD $[4,8]$. Hanachi and Shemshaki [18] reported that this could be due to decreased efficacy of the antioxidant defense mechanism, leading to increased reactive oxygen production from free radicals.

SOD converts superoxide anion to hydrogen peroxide, which is subsequently transformed to water by GSH-Rd or CAT. In blood, these antioxidant defense mechanisms offer protection to membrane lipids and proteins against oxidative damage caused by free radicals, free hemin, and iron [19]. It had earlier been documented that in stored blood, SOD, CAT, and GSH-Rd protect the blood cells and $\mathrm{Hb}$ majorly from oxidative changes [19]. In this study, activities of GSH-Rd and CAT were significantly decreased by the $21^{\text {st }}$ day of storage compared to the baseline values, whereas the MDA levels in the stored blood significantly increased from day 7 to day 42 . Findings from enzymatic activities of SOD revealed a significant increase by day 7 from the baseline reading. The recorded concurrent decrease in reduced glutathione activity alongside concurrent with an increase in oxidative modification of membrane lipids and proteins (MDA), may destabilize the membrane skeleton, thereby compromising RBCs survival.

The result of this study is dissimilar to the findings of Marjani et al. [17], Deyhim et al. [8] on human blood, and that of Udegbunam et al. [4], while comparing the oxidative changes seen in human and canine blood stored with commercially available human blood bag. In these earlier studies, decreased activities in CAT and glutathione were recorded after 7-14 days of storage while this study revealed time-dependent change from day 21 of blood storage. Nonetheless, the findings of Aslan et al. [20] on the levels of oxidative marker (MDA) showed a significant increase from day 7 till the end of the study, which agreed with this finding. Furthermore, Udegbunam et al. [4], Gultekin et al. [16], Marjani et al. [17], and also reported decreased SOD activity at days 7-14 of storage, whereas a contradictory finding of significantly increased SOD activity from day 7 to day 28 was recorded in this study. Red cells are normally protected against oxidative injury by the reduced rate of spontaneous oxidation of hemoglobin. The NADH-dependent cytochrome-b5 reductase reduces methemoglobin back into oxyhemoglobin, while cytosolic antioxidants (SOD, GSH, and CAT) neutralize the generated reactive oxygen species $[2,19]$. During blood storage, there are increased acidosis and oxygen partial pressure due to the increased spontaneous oxidation of hemoglobin to methemoglobin, and as a result, all the outlined protective mechanisms are impaired. In the face of all these activities, there is reduced antioxidant defense exposing the blood cells to oxidative stress, which is the predominant cause of blood storage lesions [2].

Pearson's product-moment correlation of the oxidative marker (MDA) with the antioxidant activity (SOD, GSH-Rd, and CAT) to determine the primary antioxidant defense in stored blood showed an association between MDA levels and activities of CAT and GSH-Rd but no association between the activities of SOD and levels of MDA. From a previously reported work on human blood, glutathione [8] and CAT [19] were documented as the primary antioxidants. The findings of this work agree with the findings of Constantinescu et al. [19], in which CAT and reduced glutathione jointly protected $\mathrm{Hb}$ from oxidative damage. Glutathione catalyzes the reduction of hydrogen peroxide by reduced glutathione (GSH-Rd) and protects $\mathrm{Hb}$ from oxidative breakdown. The erythrocyte antioxidant defense potential decreases in correlation with the increase in oxidative stress.

\section{Conclusion}

This study established that during blood storage, time-dependent changes in red cytosolic antioxidant activities occurred. This study also showed that the primary antioxidant defense of donkey blood during storage was GSH-Rd and CAT.

\section{Authors' Contributions}

OHN and URI conceived the idea. OHN and EHT wrote the first draft of the manuscript. OHN, URI, USO, and NLG were involved in the design and carried out the experimental work. OHN, URI, and EHT were involved in the analysis. The manuscript was critically read, revised, and approved for submission by all the authors.

\section{Acknowledgments}

We acknowledge the authorities of Veterinary Teaching Hospital and Veterinary Teaching Farm, Faculty of Veterinary Medicine, University of Nigeria, Nsukka, for availing us all necessary help we needed at the time of this study. The authors declare that they did not have any funding source or grant to support this study.

\section{Competing Interests}

The authors declare that they have no competing interests.

\section{Publisher's Note}

Veterinary World remains neutral with regard to jurisdictional claims in published institutional affiliation. 


\section{References}

1. Wardrop, K.J., Tucker, R.L. and Anderson, E.P. (1998) Use of an in vitro biotinylation technique for determination of post transfusion viability of stored canine packed red blood cells. Am. J. Vet. Res., 59(4): 397-400.

2. Orlov, I. and Karkouti, K. (2015) The pathophysiology and consequences of red blood cell storage. Anaesthesia, 70 Suppl 1: 29-37.

3. Okereke, H.N., Udegbunam, R.I. and Nnaji, T.O. (2019) Stability of hematological parameters of canine blood stored samples stored with citrate phosphate dextrose adenine-1 plastic vacutainers. Vet. World, 12(3): 449-453.

4. Udegbunam, R.I., Njaka, C.S., Okereke,H.N. and Udegbunam, S.O. (2019) Comparative evaluation of the in-vitro viability of canine and human blood preserved in citrate phosphate dextrose adenine-1 anticoagulated blood bag. Indian J. Anim. Res., Article Id: B-1039. DOI: 10.18805/ijar.B-1039.

5. Pichler, M.E. and Turnwald, G.H. (1985) Blood transfusion in the dog and cat. Part 1. physiology, collection, storage, and indications for whole blood therapy. Compend. Contin. Educ. Pract., 7(1): 64-71.

6. Lanevschi, A. and Wardrop, K.J. (2001) Principles of transfusion medicine in small animals. Can. Vet. J., 42(6): 447-454.

7. Michael, G.R., Tamir, K., Darrel, T., Chenell, D., Suchitra, B., Jessica, B., Shilpa, J., Andrea, M.B., Daniel, B.K. and Mark, T.G. (2015) Effects of aged stored autologous red blood cells on human endothelial function. Am. J. Respir. Crit. Care Med., 192(10): 1223-1233.

8. Deyhim, M.R., Navabi, Z., Jalili, M.A., Maghsoudloo, M. and Khoshnaghsh, F. (2014) Alternation in erythrocyte enzyme antioxidant activity during blood storage. Iran. $J$. Blood Cancer, 6(2): 69-74.

9. Sameh, M., Zainab, M., Nader, R. and Eman, A. (2009) Study of erythrocyte superoxide dismutase, plasma malondialdehyde and osmotic fragility test in psoriasis. J. PanArab League Dermatol., 20(1): 57-69.

10. Hess, J.R. (2010) Red cell changes during storage. Transfus.
Apher. Sci., 43(1): 51-59.

11. Baynes, J.W. and Thorpe, S.R. (1999) Role of oxidative stress in diabetic complications: A new perspective on an old paradigm. Diabetes, 48(1): 1-9.

12. Sinha, A.K. (1972) Colorimetric assay of catalase. Anal. Biochem., 47(2): 389-394.

13. Moron, M.A., Dipierrre, J.W. and Mannervick, B. (1979) Levels of glutathione, glutathione reductase and glutathione $\mathrm{S}$ transferase activity in rat lung and liver. Biochim. Biophys. Acta, 582(1): 67-78.

14. Stocks, J. and Dormandy, T.L. (1971) The autoxidation of human red cell lipids induced by hydrogen peroxide. $B r . J$. Haematol., 20(1): 95-111.

15. Misra, H.P. and Fridovich, I. (1972). The role of superoxide anion in the autoxidation of epinephrine and a simple assay for superoxide dismutase. J. Biol. Chem., 247(10): 3170-3175

16. Gultekin, F., Akdogan, M., Altuntas, I., Delibas, N. and Kaptanagasi, M. (2000) Changes in erythrocyte lipid peroxidation and antioxidation and antioxidation potential during storage of blood and protective effect of melatonin. Turk. J. Biochem., 25(3): 83-91.

17. Marjani, A., Moradi, A. and Ghourcaie, A. (2007) Alteration in plasma lipid peroxidation and erythrocyte superoxide dismutase and glutathione peroxidase enzyme activities during storage of blood. Asian J. Biochem., 2(2): 118-123.

18. Hanachi, P. and Shemshaki, A. (2010) The antioxidant enzymes activities in blood of physical education students after eccentric and concentric training activities. Am. Eurasian J. Agric. Environ. Sci., 7(5): 501-504.

19. Constantinescu, A.A., Dobreanu, M., Popoiu, G., Tanase, A., Sturzoiu, C. and Stoian, G. (2010) Studying the aging of banked erythrocytes using a fluorescence marker, hypericin. Genet. Biol. Mol., 11(4): 183-196.

20. Aslan, R., Sekeroğlu, M.R., Tarakçioğlu, M. and Köylü, H. (1997) Investigation of malondialdehyde formation and antioxidant enzyme activity in stored blood. Haematologia (Budap), 28(4): 233-237.

$* * * * * * * *$ 